\title{
The impact of the OECD on the development of national/international risk/safety assessment frameworks
}

\begin{abstract}
Helmut GAUGITSCH*
Environmental Impact Assessment and Biosafety, Federal Environment Agency, Umweltbundesamt, Spittelauer Laende 5, A-1090 Vienna, Austria

The role of OECD in the development of national and international risk/safety assessment frameworks is presented and discussed. The most relevant OECD bodies in this context have contributed a lot to the development of international biosafety frameworks, inter alia by organizing international conferences in the areas of food/feed and environmental safety of GMOs, focusing on practical and current scientific issues. The OECD Consensus Documents as well as the OECD Product Database have provided a good basis for risk/safety assessment frameworks and their implementation. The relevance for the OECD work in the international area is discussed, in particular, with respect to the work undertaken under the Cartagena Protocol on Biosafety, the Codex Alimentarius Commission and its work in biotechnology, as well as under the International Plant Protection Convention. An outlook and suggestions for future directions of OECD work in this area are presented.
\end{abstract}

\section{INTRODUCTION}

With respect to work on risk/safety assessment of GMOs ${ }^{1}$ the most relevant OECD Bodies are:

- The OECD Working Group on Harmonization of Regulatory Oversight in Biotechnol$\operatorname{ogy}^{2}$ (http://www.oecd.org/department/0,2688, en_2649_34387_1_1_1_1_1,00.html)

- The OECD Task Force for the Safety of Novel Foods and Feeds ${ }^{3}$ (http://www.oecd.org/department/0,2688, en_2649_34391_1_1_1_1_1,00.html).

Both were established, and are currently managed, by the OECD Joint Meeting of the Chemicals Committee and the Working Party on Chemicals, Pesticides and Biotechnology ${ }^{4}$. The Working Group was established in 1995 , first as an Expert Group; it has had its current title since 1998. The Task Force was established in 1999.

Both groups have their history in previous work of the OECD in biotechnology and biosafety and they have a similar major goal - that is to contribute to and promote international regulatory harmonization in the area of biotechnology in the OECD member countries. The

* Corresponding author:

helmut.gaugitsch@umweltbundesamt.at

${ }^{1}$ In this text the term GMO (Genetically Modified Organism) is used. For practical purposes, this term is regarded as equivalent to LMO (Living Modified Organism) or GEO (Genetically Engineered Organism).

${ }^{2}$ In short: the OECD Working Group.

${ }^{3}$ In short: the OECD Task Force.

${ }^{4}$ In short: the Joint Meeting. outreach activities are intended to ensure that this impact goes even beyond the OECD member countries. Typically, the national delegations to the two groups are comprised of government officials being responsible for decision making in the area of environmental or food/feed safety aspects of GMOs. Observers and invited experts also participate, including non-member countries, international organizations and industry (through OECD's Business and Industry Advisory Committee - BIAC). The two groups have programs of work valid for three years, which are developed by the group and adopted as appropriate by the Joint Meeting as their supervisory body. These programs can be reviewed, adapted and extended for further terms. Both groups have contributed much to the international arena concerning GMO risk/safety assessment frameworks, which the following sections will summarize.

\section{INTERNATIONAL RELEVANCE OF THE OECD WORK IN RISK/SAFETY ASSESSMENT}

\section{The G8 Report}

At the request of the G8 Heads of States and Government, the Secretary General of the OECD on behalf of the OECD Council presented an OECD study on "The implications of biotechnology and other aspects of food safety" at the G8 Summit in Okinawa/Japan in July 2000 (OECD, 2000a, 2000b). This report inter alia included reports from the two groups mentioned above, the OECD Working Group and the OECD Task Force. Both reports gave an overview of the state of the art concerning 
risk/safety assessment of GMOs from an environmental perspective (Working Group) and a food/feed safety perspective (Task Force). These reports also identified future needs. Both reports identified clearly what can and should be done at the international level in spite of clear national differences. These two reports were complemented by a report from a newly established OECD Ad Hoc Group on Food Safety. This group had been established by the OECD Council just for this particular purpose and provided an analytic inventory of national and international systems. Furthermore, two reports were added, one on an OECD consultation with civil society, one on a Conference on GM Foods, organized by the OECD and hosted by the UK (Edinburgh, February/March 2000). This G8 report was an important point for the OECD to increase international visibility and outreach.

\section{The post G8 period - International Conferences}

After the finalization and publication of the G8 report, the OECD started a series of well-recognized and received international activities.

In July 2001 the Conference "New Biotechnology Foods and Crops: Science, Safety \& Society" was jointly sponsored by the UK and OECD and took place in Bangkok, Thailand. The major aims were to discuss how to integrate the best available scientific knowledge in food safety assessment and how to ensure increased stakeholder involvement. Many experts not only from OECD member states, but also from non-member countries as well as various relevant intergovernmental organizations (IGOs), such as FAO, WHO, Codex, IPPC, WTO, SCBD, etc., participated actively. The need for improved capacity building, as well as the key role of intergovernmental organizations in international consensus building on GMO risk/safety issues were major results and recommendations from this conference (OECD, 2001).

In November 2001, the International Conference "LMOs and the Environment" took place in RaleighDurham/USA. This conference was organized by the OECD and hosted by the US Government. The discussion focused on environmental issues concerning GMO risk/safety assessment. On the one hand, the state-of-theart in this area was presented and discussed from various countries and backgrounds; on the other hand, future challenges and possible ways forward were identified. As one of the key recommendations, necessary improvements for environmental assessment methodologies were highlighted (OECD, 2002a).

The OECD Workshop on Review of Consensus Documents and Future Work in Harmonization, hosted by the US Government in Washington in October 2003, was designed as an internal Workshop of the OECD Working Group with the participation of observers from non- member countries and notifiers. The main goal was to assess what has been achieved by the work and publications of the Working Group over the last couple of years, mainly the Consensus Documents. In addition, future work areas and possible ways of prioritizing the work by focusing on the most important existing and emerging issues were identified.

All these conferences had a couple of characteristics in common. First they involved a broad participation of intergovernmental organizations, such as FAO, Codex, WHO, SCBD, etc. In addition they allowed and supported a broad participation of stakeholders. Thereby representatives from the responsible government authorities had a valuable and important opportunity to interact with notifiers, scientists and non-governmental organizations. Third, it is very important to note that all of these conferences involved, to an increasing extent, representatives from non-member countries. This involvement is a key contribution to OECD's work on outreach in ensuring its global usefulness. The conferences with their varying but complementary focuses gave an excellent summary of the "state-of-the art" concerning risk/safety assessment in biotechnology. At the same time they had a strategic focus, identifying and recommending future needs and priorities. With this approach, the OECD tries to ensure that it responds in a timely way to new and emerging issues in GMO product development as well as in risk/safety assessment methods.

The major result of the "Bangkok Conference" can be characterized as the formation of an informal network of intergovernmental organizations having an interest in biotechnology and biosafety. The "Raleigh-Durham Conference" gave a major initiative to the now started work of the OECD on parameters for environmental risk/safety assessment. Finally, the "Washington Workshop" gave the major input to the work within OECD on the so called "Points to consider document" (OECD, 2006a). In Washington the starting point for a priority-setting exercise within the OECD Working Group was given. The input from non-member Countries was strengthened and has become an integral part of OECD's work.

\section{EXAMPLES OF MAJOR “PRODUCTS” OF OECD RELEVANT FOR INTERNATIONAL BIOSAFETY}

Both the Consensus Documents as well as the OECD product database can be regarded as nationally and internationally very relevant for GMO risk/safety assessment.

\section{The OECD Consensus Documents}

The recent compilation "Safety Assessment of Transgenic Organisms" (OECD, 2006b) contains two volumes 
of currently available Consensus Documents (more than 20 have been published by the Working Group, about 15 are currently under development). In February 2005 OECD published "An Introduction to the Biosafety Consensus Documents of the OECD Working Group" (OECD, 2005). This publication summarizes the approach to develop and the usefulness of the OECD Consensus Documents, inter alia by highlighting their importance for risk/safety assessment. They do not substitute for a risk/safety assessment but are an important contribution to it. They provide a "snapshot" of the information available, for example, on the biology of a crop plant which may be the target for genetic modifications. They contain the core set of information on a consensus basis as agreed upon by the OECD member states. This baseline scientific knowledge is intended to contribute to a common basis for risk/safety assessment. They are prepared by a lead country approach, that means one or more lead country develops the draft(s) and these are discussed and finalized with the input from all interested member countries as well as those non-member countries that participate in the work.

The OECD Working Group has so far produced more than 20 Consensus Documents, on the biology of crop plants (e.g. maize, oilseed rape, wheat) as well as on some traits (coat-protein mediated virus resistance, herbicide tolerance against glyphosate or glufosinate) with a modular approach. The next step the Working Group undertook was the development of the "points to consider document" (OECD, 2006a), which suggests a standardized structure for future biology consensus documents, which will also be relevant for review and adaptation of existing ones. It contains the core set of information elements that a biology consensus document should address; it also provides a rationale why these information elements are relevant.

The OECD Task Force has so far produced 13 Consensus Documents, mainly on the biology of crop plants (e.g. maize, sugarbeet, soybean), and many more are under development. These focus on the compositional characteristics of the plants (nutrients, vitamins, secondary metabolites, etc.), and provide a basis for a comparative approach between food derived from modern biotechnology and its conventional counterpart. The Task Force developed and in April 2006 published "An Introduction to the Food/Feed safety Consensus Documents of the Task Force" (OECD, 2005).

Consensus Documents are used extensively by applicants and regulatory authorities. There is no legally binding commitment to use them, however, these stakeholders use the information available in the Consensus Documents "in good faith" and this has worked well so far.

\section{The OECD product database}

Via the following website the OECD product database can be accessed:

http://www.oecd.org/biotech/productdatabase. It contains information on products approved in OECD member countries. The Unique Identifier assigned to the approved product on the basis of the OECD Guidance is a key to each product in the database. In the database, various types of information are available, such as the Unique Identifier (UI), the host organism, the introduced trait/genes. Currently, the database is subject to system upgrading, which may result in a change of appearance soon. Screenshots of the database show its structure and usefulness for the national and international community.

\section{RELEVANCE TO INTERNATIONAL FORA}

The work of OECD in GMO environmental risk/safety assessments and the above mentioned "products" are relevant for the work in various international fora, such as the Cartagena Protocol, the Codex Task Force on Foods derived from biotechnology, and the International Plant Protection Convention (IPPC).

\section{Cartagena Protocol on Biosafety}

A Memorandum of Understanding (MoU) has been developed and adopted between the SCBD as the Secretariat to the Cartagena Protocol as well as the OECD. This Memorandum, which is periodically under review, contains terms for collaboration between the two institutions, especially concerning the OECD product Database and the Biosafety Clearing House (BCH, see http://bch.biodiv.org).

Unique Identifiers have been assigned to approved products on the basis of the OECD Guidance for the Designation of a Unique Identifier for Transgenic Plants (OECD, 2002b). On the basis of interoperability with the $\mathrm{BCH}$, these unique identifiers are submitted to the $\mathrm{BCH}$ for its compilation of LMO-FFP products approved in Parties of Export according to Article 11.1 of the Protocol.

\section{The Codex Task Force on Foods derived from biotechnology}

The first Task Force having worked until 2003 has developed:

- principles for the risk analysis of foods derived from modern biotechnology; 
- a Guideline for the conduct of food safety assessments of foods derived from recombinant-DNA plants (CODEX, 2003).

The second Task Force with a new mandate has started its work in 2005, and inter alia will develop guidance on foods derived from rDNA animals.

The Consensus Documents developed by the OECD Task Force may be very useful for the deliberations of Codex. In addition the contribution of OECD to a possible future information mechanism for so called "asymmetric approvals" (GMO products approved in one or more countries but not in others) will be assessed.

\section{The International Plant Protection Convention (IPPC) under FAO}

Under IPPC, phytosanitary risks that may be associated with LMOs are discussed, amongst many other things. An international standard for phytosanitary measures (ISPM), No 11 with the title "Pest risk analysis for quarantine pests including analysis of environmental risks of LMOs" (IPPC, 2004) has been developed by IPPC with involvement of other IGOs, such as OECD and SCBD. It will have to be assessed, whether and how, the work of OECD, especially its Consensus Documents, may assist the work of the IPPC. In particular it would be interesting to see if and how the work in the environmental area may assist work on pest risk analysis.

\section{OUTLOOK - FUTURE DIRECTIONS}

The issues mentioned above clearly show that OECD has contributed much in the past and continues to make substantial contributions to national and international risk/safety assessment frameworks. The future work of OECD should continue in this direction and should ensure the global usefulness of the work by co-operating and establishing synergies with other international organizations (IGOs). The involvement of non-member countries should be intensified in this context. Urgent needs identified by the various stakeholders (in particular regulators and scientists) should be addressed in an appropriate manner, and work items should be prioritized for reasons of efficiency. The global information exchange mechanisms in biotechnology and biosafety should be improved, and OECD with the experience concerning the OECD Product Database can play its role here. The existing Consensus Documents should be updated where necessary and remaining gaps should be filled. This will ensure scientific state-of-the art and adequate reaction to technical progress. The work OECD has started in the area of "parameters for environmental risk/safety assessment" is regarded by countries as an extremely important piece of work which should be further developed and concluded on a consensus basis as soon as possible.

\section{REFERENCES}

CODEX (2003) Guideline for the Conduct of Food Safety Assessment of Foods Derived from Recombinant-DNA Plants (http://www.codexalimentarius.net/download/standards/ 10021/CXG_045e.pdf)

International Plant Protection Convention, the Secretariat of (2004) International Standard for Phytosanitary Measures No. 11 Pest Risk Analysis for Quarantine Pests Including Analysis of Environmental Risks and Living Modified Organisms (https://www.ippc.int/servlet/BinaryDownloaderServlet/ 34163_ISPM_11_E.pdf?filename= 1146658377367_ISPM11.pdf\&refID=34163)

OECD (2000a) Report of the Working Group on Harmonisation of Regulatory Oversight in Biotechnology (http://www.olis.oecd.org/olis/2000doc.nsf/LinkTo/ C(2000)86-ADD2)

OECD (2000b) Report of the Task Force for the Safety of Novel Foods and Feeds (http://www.olis.oecd.org/olis/2000doc.nsf/LinkTo/ C(2000)86-ADD1)

OECD (2001) Rapporteurs Report for the Conference on New Biotechnology Foods and Crops: Science, Safety and Society, Bangkok (http://www.oecd.org/ dataoecd/18/31/1829717.pdf)

OECD (2002a) Final Rapporteurs' Report - LMOs and the Environment: An International Conference, Raleigh-Durham

OECD (2002b) OECD Guidance for the Designation of a Unique Identifier for Transgenic Plants (http://www.olis.oecd.org/olis/2002doc.nsf/LinkTo/envjm-mono(2002)7)

OECD (2005) An Introduction to the Biosafety Consensus Documents of OECD's Working Group on Harmonisation of Regulatory Oversight in Biotechnology (http://appli1.oecd.org/olis/2005doc.nsf/linkto/env-jmmono(2005)5)

OECD (2006a) Points to Consider for Consensus Documents on the Biology of Cultivated Plants (http://appli1.oecd.org/olis/2006doc.nsf/linkto/env-jmmono(2006)1)

OECD (2006b) Safety Assessment of Transgenic Organisms: OECD Consensus Documents 